\title{
GEORG SIMMEL E A "SOCIOLOGIA DA POBREZA"
}

Anete B. L. Ivo*

\section{ALGUNS ELEMENTOS SOBRE A OBRA E $O$ AUTOR}

Este texto busca trazer para os leitores uma visão sintética do livro de Georg Simmel - Les Pauvres $^{1}$ (1907) -, editado pela primeira vez em língua francesa, em 1998, precedido de uma longa apresentação de Serge Paugam e Franz Shultheis, sob o título Naissance d'une sociologie de la pauvrété. Ele tem uma extraordinária atualidade, não só por um conjunto de análises que auxiliam

* Doutora em Sociologia (UFPE). Professora do Programa de Pós-graduação em Ciências Sociais da UFBA e pesquisador sênior do Centro de Recursos Humanos (CRH/UFBA). Rua Caetano Moura, $99-1^{\circ}$ sub-solo. Salvador, Bahia, Brasil.40.210-340. anetivo@hotmail.com

${ }^{1}$ Esse texto foi traduzido do original em alemão Der Arme, que está no singular. O tradutor, Bertrand Chrokrane, considerou adequado traduzi-lo no francês na forma plural - Les Pauvres. A primeira versão foi publicada numa revista sob o título Sociologie de la Pauvrété, de 1907, mas integrou a Grande Sociologia de Simmel, em 1908. O texto foi publicado em 1965, na revista americana Social Problems (v.13, n.2, p.117 et.), acompanhado de uma nota sobre o autor escrita por Everett C. Hughes e de um artigo de L.A. Loser sobre a sociologia da pobreza (Cf. Paugam; Schulteis, 1998). Em 1971, integrou o livro George Simmel. On individuality and social forms. Textos selecionados editados por D. Levine, Chicago, University of Chicago Press, p.172 com o título "The Poor”. (Cf. Thomas, 1998). Não há versão em português. As referências aqui citadas foram traduzidas por mim. na definição de princípios gerais de novos desenhos de programas de "renda mínima de cidadania”, ${ }^{2}$ como encaminha, no plano teórico e analítico, uma fecunda análise sobre a estruturação social. É um texto clássico do início do século XX, escrito num contexto em que começaram a surgir, na Alemanha, propostas de sistemas de proteção social centrados no Seguro Social. Para Serge Paugam e Franz Shultheis, a partir de uma rigorosa e fecunda abordagem construtivista, Simmel rompe, nesse texto, com as concepções substancialistas, muito usadas nos debates científicos e políticos sobre a pobreza, oferecendo uma contribuição sociológica aos estudos nessa área. Em vez de considerar a "sociologia da pobreza" como um campo específico da sociologia, Simmel remete o seu estudo às questões fundamentais da teoria social e do método, mais referidas à constituição e à forma dos laços e vínculos sociais na modernidade (p. 1).

Tomando como ponto de partida as relações intersubjetivas da obrigação da dádiva, o autor extrai proposições teóricas mais amplas, como

${ }^{2}$ Ver a respeito, para o Brasil, Suplicy (2002). 
as relações entre a ética, a moral e a sociedade, na construção da dádiva e da caridade; das relações entre o indivíduo (pobre) e as coletividades (Estado nacional, municípios); da parte e do todo (de uma perspectiva metodológica); da generalidade (noção abstrata da pobreza) com as formas regulatórias (assistência) e sua objetivação da ação social (as formas concretas assumidas pelas instituições públicas ou privadas da assistência). Ou seja, ele busca contribuir para uma teoria geral $d a$ sociedade, através de um objeto aparentemente "marginal", como o estatuto do pobre frente à sociedade em geral, num contexto de constituição do Estado moderno na Europa (e na Alemanha, em particular) no início do século XX. Para ele, é a assistência que alguém recebe publicamente da coletividade que determina a sua condição sociocultural de "ser pobre". A condição de "ser assistido”, portanto, constitui a marca identitária da condição do "pobre" e o critério de seu pertencimento como uma camada específica da sociedade inevitavelmente desvalorizada, vez que definida pela desigualdade e dependência dos demais. Essa condição significa receber dos "outros", ou da coletividade, sem poder definir-se através de uma relação de complementaridade e de reciprocidade frente aos demais, em condições de igualdade. Mas, ao reconhecer a condição política da cidadania, Simmel ultrapassa, na análise, essa condição estigmatizada do "assistido". Assim, é no âmbito da política e da cidadania que ele concebe as saídas para os aspectos socioculturais da dependência de assistência. Assim, nesse livro, o que interessa a Simmel

... não é a pobreza em si nem a entidade dos pobres em si mesmos, mas as formas institucionais que eles assumem numa dada sociedade num momento específico de sua história. Essa sociologia da pobreza, em realidade, é uma sociologia dos laços sociais (Simmel [1907], 1998).

Simmel assume, explicitamente, um esforço analítico da sociologia nas interpretações do fenômeno da pobreza. "Aqui se manifesta uma oposição fundamental entre categorias sociológicas e éticas”, diz ele. Com traços claramente influencia- dos por Max Weber e Emmanuel Kant, ${ }^{3}$ ele sublinha certo número de tensões e significados numa análise das instituições sociais regulatórias da pobreza. Assim, a partir do princípio de assistência, Simmel levanta um conjunto de tensões e paradoxos que ameaça o sistema social na sua globalidade, mas estabelece, ao mesmo tempo, formas de regulação que atenuam seus efeitos e permitem a interdependência entre indivíduos e grupos de indivíduos, mesmo que resultem em relações desiguais e às vezes conflituosas. "A pobreza [...] é não apenas relativa, mas construída socialmente. Seu sentido é aquele que a sociedade lhe atribui" (Paugam; Shultheis, 1998, p.15).

A passagem que ele faz entre uma sociologia das formas associativas (no caso, a assistência) e o processo do conhecimento da realidade, que envolve a passagem do particular ao global, das relações intersubjetivas da dádiva às formas coletivas do Estado, se constitui na natureza e no constructum dessa obra.

Simmel não aborda diretamente [...] as experiências vividas da pobreza, sua análise o conduz de forma lógica a apresentar uma das dimensões essenciais da situação dos pobres que decorrem da situação da assistência (p.17-18).

Para ele, a sociedade não é constituída pelos indivíduos, mas preexiste a eles e os constitui, socializando-os. ${ }^{4}$ Essa perspectiva o aproxima de Marcel Mauss, ${ }^{5}$ que supera o objetivismo de Durkheim, ${ }^{6}$ ao reintroduzir a contribuição da cons-

${ }^{3}$ Kant, em sua obra Fondements de la Métaphysique des Moeurs distingue os julgamentos analíticos dos julgamentos sintéticos. Simmel emprega os predicados de Kant para esclarecer a dualidade das noçõ̃es de "obrigação" e "direito". (Simmel, 1998, p.40, N.T.)

4 No entanto, ele não reduz a sociabilidade à intersubjetividade, mas leva em conta explicitamente a mediação da cultura e das instituições sociais.

${ }^{5}$ Marcel Mauss, no Essai sur le Don [1924], mostrou que os "fatos sociais totais", que mobilizam e colocam em movimento a "totalidade da sociedade" ou, pelo menos, "um grande número de instituições", deixam "perceber o essencial, o movimento do todo, o aspecto vivo, o instante fugidio em que a sociedade ou os homens tomam consciência sentimental de si mesmos e de sua situação em face do outro" (Cf. Vandenberghe, 2005, p.19-20).

${ }^{6}$ Durkheim manteve uma posição ambivalente em relação à obra de Simmel: se, de um lado, o seu positivismo criticava as abordagens compreensivas da sociologia alemã, de outro, foi ele próprio quem denunciou a condi- 
ciência na constituição dos fatos sociais (Cf. Vandenberghe, 2005, p.19) e precede a teoria das configurações sociais de Norbert Elias.

É considerado um autor polêmico pelos objetos de estudo aparentemente díspares de que se ocupou (a moda, o estrangeiro, o dinheiro, a pobreza, etc.) e pela herança multidisciplinar de sua obra, que articula a sociologia das formas à filosofia da moral e da cultura. ${ }^{7}$ No caso da pobreza e dos pobres, ele associa as diversas concepções que governam a ação moral no ato de "dar e receber" à forma empírica da assistência.

Na medida em que um ser é social, a cada uma das obrigações corresponde um direito associado ao outro. [...] Mas, uma vez que cada pessoa que tem uma obrigação, possui igualmente [...] direitos, forma-se uma rede de direitos e obrigações na qual o direito sempre é o primeiro e o decisivo elemento e em que a obrigação é apenas o seu correlativo... (Simmel [1907], 1998, p.39).

\section{A "OBRIGAÇÃO SOCIALIZADA" DA SOCIEDA- DE EM RELAÇÃO AOS POBRES EM SIMMEL}

O ponto de partida de Simmel é a trama dos direitos e obrigações, na qual se constitui a socialidade humana, e que evolui do plano interativo interpessoal até formas associativas e relações cada vez mais amplas. Ele analisa a pobreza e a condição de ser pobre ${ }^{8}$ numa dada sociedade, a partir da relação dos direitos e obrigações das prestações, revelando um paradoxo inscrito nessa relação do ponto de vista ético-ideal: os "deveres” (as prestações, as dádivas), como princípios morais, nada mais são do que imperativos

ção injusta de Simmel na posição de privatendozent na Universidade alemã, de maneira pertinente, como a de um "proletariado acadêmico", durante uma viagem que

fez à Alemanha (Cf. Paugam; Shultheis, 1998, p.12).

${ }^{7}$ Para entender sociologicamente as particularidades da obra de Simmel por fenômenos da marginalidade social, é preciso levar em conta o contexto histórico no qual ele desenvolveu os seus trabalhos, numa Alemanha marcada por um anti-semitismo aberto e pela sua condicão de intelectual judeu. Essa condição levou-o a perceber os estigmas e as violências simbólicas cometidas contra estrangeiros, possibilitado pelo seu estatuto de foreign elements - uma experiência constitutiva, ao mesmo tempo, de uma espécie de habitus coletivo (Cf. Paugam; Shultheis, 1998, p.11).

${ }^{8}$ Duas questões analiticamente diferentes. internalizados sobre nós mesmos, com toda autonomia do "Eu", independentemente de qualquer elemento externo. No entanto, na medida em que a prestação deriva de um direito - no sentido amplo do termo, incluindo, entre outros elementos, o direito legal -, a relação entre os indivíduos, impregnada dos seus valores morais, determina e fundamenta o seu comportamento em relação ao direito do "outro" como elemento principal. Segundo Joseph (2003),

...do ponto de vista "moral” a motivação de um "dever" é subjetiva e autônoma e não se origina da situação do outro. Somente no "direito", que recobre tanto o domínio jurídico como as relações de prestações, é que o "outro" aparece como fonte de "obrigação (p. 322).

A obrigação de dar não deriva de um direito do outro, mas de uma imposição moral daquele que dá, determinada pela sua própria moralidade e responsabilidade. Só no campo do direito é que ela se volta para "o outro". Esse dualismo, que governa o desenvolvimento das ações morais, se expressa empiricamente nas diversas concepções de assistência aos pobres nas instituições da sociedade moderna: na forma como as coletividades (Estado, sindicatos, família, etc.) se dedicam aos pobres. Para Simmel, no entanto, no âmbito da "obrigação" da dádiva, o pobre desaparece como fim da ação. Mesmo no plano das ações circunscritas a universos restritos da caridade e (ou) da assistência, a exemplo das ajudas no seio familiar ou na experiência sindical das caixas de desemprego dos ingleses, Simmel mostra que o "pobre" não é o objeto da prestação, mas são outros fins coletivos e não o próprio pobre que mobilizam e motivam o ato da doação, a exemplo das eventuais preocupações dos membros de uma família com sua reputação, no primeiro caso, ou a proteção dos salários de uma categoria de trabalhadores, no segundo (p.48-49). No caso da assistência pública do Estado, ela é imposta pela suposta idéia dos riscos da pobreza à ordem social:

... a fim de que os pobres não se tornem inimigos ativos e perigosos da sociedade, para tornar suas reduzidas energias mais produtivas e, enfim, para 
impedir a degeneração de sua progenitura. O homem pobre, enquanto pessoa com sua própria percepção de sua posição [...] teve pouca importância... (Simmel [1907], 1998, p.47).

É a partir dessa concepção de obrigação socializad $a^{9}$ que Simmel desenvolve sua crítica. Para ele, o paradoxo dessa obrigação, unificada na idéia do bem-comum, só pensa o interesse geral a partir de uma posição centralista e teleológica, ignorando o interesse daqueles a quem se assiste.

Esse sentido acaba por definir um caráter meramente mitigador para a política da assistência em relação aos pobres. Assim, Simmel critica e esclarece:

O fim da assistência é precisamente mitigar certas manifestações extremas de diferenciação social, a fim de que a estrutura possa continuar a se fundar sobre essa diferenciação. Se a assistência se fundasse sobre os interesses do pobre, em princípio, não haveria nenhum limite possível quanto à transmissão, o que conduziria à igualdade de todos. Mas, uma vez que o objetivo é o todo social - os círculos políticos, familiares ou sociologicamente determinados -, não há qualquer razão para ajudar ao pobre senão a manutenção do status quo social (p.49).

Na sua crítica, ele reconhece que a assistência se funda nos limites da própria estrutura social e, dessa forma, contrapõe-se a quaisquer outras aspirações, de caráter socialista ou comunista, já que, por princípio, essas concepções implicariam a superação mais radical de tal estrutura.

Essas dimensões (éticas e sociológicas) da moral e da estrutura social estão implícitas na natureza da ação do Estado e do direito do assistido, nas sociedades modernas.

Nós encontramos sempre o princípio segundo o qual o Estado tem obrigação de assistir os pobres, mas esta obrigação não corresponde a um direito à assistência dos pobres. Como foi declarado claramente na Inglaterra [...] o pobre não tem recurso a nenhuma ação de compensação, quando ilegalmente recusam-se a ajudá-lo. Toda relação entre obrigações e direitos está [...] acima e além do pobre. O direito correspondente à obrigação do Estado de assistir ao pobre não é o direito do pobre, mas aquele de qualquer cidadão, onde os impostos gastos com os pobres sejam de tal monta e aplicados de tal maneira, de forma a que os

${ }^{9}$ Para usar uma expressão de Isaac Joseph (2003, p.323). objetivos públicos da assistência aos pobres sejam verdadeiramente alcançados (p.50-51).

Ou seja, o direito do pobre é de ordem geral e diz respeito aos controles sobre os recursos públicos, distinguindo-se do direito individual, que lhes permite requerer contra eventuais injustiças na aplicação dos benefícios, diferentemente dos trabalhadores.

Por conseqüência, no caso de negligência da assistência aos pobres, estes não poderiam recorrer contra o Estado, enquanto outros elementos que sofreram indiretamente de tal negligência o podem (Simmel [1907], 1998, p.51). ${ }^{10}$

Assim, ele faz uma crítica à "exclusão do pobre” na cadeia teleológica da ordem social, que, ao negar-lhe um estatuto de finalidade da ação social, não lhe permitiria sequer representar-se politicamente. Para ele, a assistência aos pobres, dentro dessa significação, não passa de uma "aplicação de meios públicos para fins públicos” (p. 51), e continua sua crítica: “... cada vez que esse interesse centralista prevalece, a relação entre direito e obrigação pode ser modificada em nome de considerações utilitaristas” (p. 52). Essa dimensão puramente utilitarista se expressa por ser a assistência, ${ }^{11}$ àquela época, o único ramo da administração moderna no qual os interessados não tinham qualquer participação nas definições das políticas. Assim, para Simmel, “... uma vez que os pobres se encontram excluídos dessa teleologia, [...] é lógico que o princípio da autogestão [...] não se aplica no caso dos pobres e de sua assistência” (p.51-52).

Simmel vai ultrapassar essa visão centralista (e utilitarista) do pobre em relação aos interesses gerais, considerando a sua condição de cidadania. Para ele, o pobre distingue-se de qualquer outro tipo de intervenção do Estado, pois:

${ }^{10}$ Em uma das passagens de sua análise, ele explicita claramente a diferença entre o "direito à assistência" dos pobres e os direitos sociais dos trabalhadores, juridicamente regulados e que podem ser requeridos, quando seja necessário.

${ }^{11}$ No contexto analisado por Simmel, a condição da assistência o tornava excluído do direito político do voto. E é essa condicão que o leva a desenvolver sua crítica, reafirmando o direito dos assistidos no âmbito civil e político da cidadania. 
Os pobres não são apenas pobres, ${ }^{12}$ eles são também cidadãos. Enquanto tais, eles participam dos direitos que a lei atribui à totalidade dos cidadãos de acordo com a obrigação do Estado de prestar assistência aos pobres. Para utilizar a mesma metáfora [da função de um canal para a os vizinhos], digamos que os pobres sejam, ao mesmo tempo, o canal e os vizinhos, da mesma forma como seriam os cidadãos mais ricos (Simmel [1907], 1998, p.55). ${ }^{13}$

Essa dimensão da cidadania resgatada por Simmel recoloca a discussão da pobreza no âmbito da política. Ele distingue o tratamento da pobreza de uma questão puramente gestionária sobre os limites da seguridade (os impostos), ou da lógica de regulação do mercado de trabalho na luta de classes (o papel do excedente) e considera que, num contexto republicano, o lugar do pobre está na comunidade cívica, de um cidadão em relação a um Estado. Com base nesse entendimento, ele explicita a posição particular e paradoxal do pobre na sociedade moderna, do ponto de vista sociológico:

Sociologicamente, o importante é compreender que a posição particular que os pobres assistidos ocupam não impede sua integração no Estado, como membros de uma unidade política total. Apesar de sua situação em geral tornar sua condição individual um fim externo ao ato de assistência, e, por outro lado, um objeto inerte, destituído de direitos nos objetivos gerais do Estado, [...] que parecem colocar os pobres fora do Estado, eles estão ordenados de forma orgânica no interior deste. (p.55)

Ao esclarecer essa posição problemática do pobre "excluído" (da cadeia dos fins sociais) como socialmente desqualificado, mas cidadão e membro integrante da sociedade política, ele explicita os limites e as ambigüidades conceituais da noção de "exclusão social”, elemento que será posteriormente objeto de crítica de outros autores. ${ }^{14}$

${ }^{12}$ Aqui ele dialoga possivelmente com a posição e situação do pobre criticada por Tocqueville, como uma posição social desqualificadora.

${ }^{13}$ Essa consideração o distancia da concepção desenvolvida por Tocqueville, cem anos antes, na Mémoire sur le Paupérisme, para quem a questão da assistência é função da caridade privada.

${ }^{14}$ A exclusão social é uma categoria da ação pública em relação à pobreza, na França. Os limites críticos dessa categoria foram analisados por inúmeros autores. Robert Castel (1995) critica o caráter estático da noção, mostrando que ela é o resultado de um processo social e não se constitui apenas de um estado. ....como pobres, eles pertencem à realidade histórica da sociedade que vive neles e acima deles e constituem um elemento sociológico formal, como o funcionário ou o contador [...]. Os pobres estão mais ou menos na posição do estrangeiro que se encontra [...] materialmente fora do grupo no qual ele reside (p.55-56).

Mas, considerando, sobretudo, o princípio da reciprocidade inscrito na experiência intersubjetiva da dádiva, ponto de partida de sua análise, e levando em conta, certamente, as críticas de liberais e mesmo dos marxistas sobre o caráter da "dependência”, inerente à lei da assistência, ele esclarece:

Em princípio, aquele que recebe uma esmola dá também alguma coisa; há uma difusão de efeitos indo dele ao doador e é precisamente o que converte a doação em uma interação, em um acontecimento sociológico. [...] Mas se [...] o recebedor da esmola continua completamente excluído da cadeia teleológica do doador, se os pobres não preenchem outro papel senão o de servir de caixa coletora de esmola [...], a doação não é um fato social, mas um fato puramente individual. (Simmel [1907], 1998, p.56-57)

E, ultrapassando a dimensão puramente individualista, ele restabelece, mais adiante, o princípio da troca entre os assistidos e a coletividade:

A coletividade social recupera indiretamente os frutos de sua doação social, reabilitando sua atividade econômica, preservando sua energia física, impedindo seus impulsos que conduzem ao uso dos meios violentos com o fim de se enriquecer. [...]

A teleologia da coletividade pode tranqüilamente passar por cima do indivíduo e retornar sobre ela mesma [coletividade], sem se deter sobre ele [o indivíduo assistido]. A partir do momento em que o indivíduo pertence ao todo, ele está, conseqüentemente, colocado, desde o início, no ponto final da ação e não [...] fora dela (p.57-58).

A partir desses desdobramentos lógicos, ele extrai os significados da exclusão dos pobres, resgatando, ao mesmo tempo, sua condição de sujeitos sociais:

A exclusão singular à qual os pobres são submetidos pela comunidade que os assiste é característica da função que eles preenchem na sociedade, como membros dela, numa situação particular. Se, tecnicamente, eles são objetos menores, num sentido sociológico mais amplo eles são também sujeitos que, como outros, constituem uma realidade social (p.61). 
Considerando as incitações morais implícitas ao ato da dádiva, ele analisa as implicações de uma eventual interrupção do ato da assistência:

Se [...] todo altruísmo, toda boa ação, todo autosacrifício não é senão um dever e uma obrigação, no caso individual, este princípio pode ser manifestado de tal forma, que toda assistência [...] representa o cumprimento de um dever que não se esgota após o primeiro gesto, mas continua a existir de fato [...]. Segundo tal princípio, a assistência prestada a alguém seria o ratio cognoscendi, o sinal que nos mostra que uma das linhas ideais da obrigação entre os homens [...] revela aqui seu aspecto intemporal nos efeitos contínuos do vínculo estabelecido (Simmel [1907], 1998, p.65).

Por fim, encerrando a primeira parte do livro, Simmel vai mostrar duas dimensões importantes. A primeira é o caráter relativo da pobreza, que se diferencia e se amplia, na medida em que ela se manifesta numa sociedade mais diferenciada e estratificada. No entanto, o caráter dessa relatividade nem sempre é visível. Joseph (2003), sintetizando a argumentação de Simmel, esclarece a tensão existente na compreensão da dádiva:

A dádiva é uma prática pública cuja forma da esmola supõe maior distância social; ou uma prática privada que na forma de socorro supõe mais intimidade. No entanto, segundo Simmel, a prática da dádiva torna-se mais difícil quando a distância social se restringe (no âmbito público); ou quando a distância social aumenta (no privado) (p.327).

Essa contradição entre a ação pública e privada da assistência é discutida por Simmel a partir do papel e dos limites de ação das municipalidades nessa matéria. Para Simmel, a assistência aos pobres tornou-se uma obrigação abstrata do Estado, na qual a municipalidade não é mais o seu ponto de partida, mas apenas um ponto onde se opera a transferência e a transmissão da assistência.

Os funcionários (locais) se conduzem na relação com os pobres como representantes da coletividade (que lhes paga o salário), diferentemente dos agentes do setor privado, que trabalham mais como seres humanos, pelo aspecto homem a homem e menos pelo aspecto objetivo (p.68).

A segunda questão que ele apresenta diz respeito ao limite mínimo da ação pública da assistência, que, ao envolver interesses amplos de uma coletividade, supõe limites mínimos relativos no seu encaminhamento. Essa dimensão "dos mínimos” de uma ação de natureza coletiva toma por base o seguinte pressuposto relativo à dádiva: cada um quer dar o mínimo possível. E esse pressuposto subjuga o princípio da lógica da necessidade no seu plano da ação empírica concreta:

O direito válido para todos é designado como um mínimo ético [...]. O direito ao trabalho reivindicado por todos só pode se aplicar àqueles que apresentem um mínimo em relação à sua dignidade; o pertencimento a um partido exige [...] que se reconheça o mínimo de princípios. [...] Este mínimo social encontra sua expressão mais acabada no caráter negativo [...] dos interesses das massas (Simmel [1907], 1998, p.70). ${ }^{15}$

Na terceira e última parte do livro, ele detalha em que consiste o mínimo da assistência aos pobres, o que, em realidade, significa "salvar alguém da falência física”. Ele analisa, então, que quaisquer ações de proteção mais abrangentes exigiriam critérios menos unívocos. E, do ponto de vista objetivo, "ao se colocar toda a assistência nas mãos do Estado, a medida normativa decorre não somente dos pobres, mas também do interesse do Estado. Assim, a medida da regulação deve se preocupar seja com o excesso [o montante do benefício em relação à coletividade], seja com sua falta [sobre a necessidade dos indivíduos]" (p.79-80). Com essas considerações ele esclarece dilemas na definição da assistência pública, que se referem à definição dos "mínimos sociais" das políticas de assistência social.

Por fim, Simmel define os significados dos pobres na sociedade em geral:

A classe dos pobres, particularmente na sociedade moderna, constitui uma síntese sociológica única. Em relação à sua significação e seu lugar

\footnotetext{
${ }^{15}$ A partir dessa consideração, Simmel, na segunda parte do seu texto, desenvolve uma análise de natureza lógica sobre os limites de uma ação coletiva assentada sobre princípios gerais, o que significa um acordo e um limite restrito sobre o qual não é possível transigir, não impedindo, no entanto, que se possam ampliar os benefícios. O caráter que une o grande círculo das coletividades se sobressai nas normas mínimas.
} 
no corpo social, ela possui grande homogeneidade; no entanto, no que se refere à qualificação individual de seus elementos, ela falta completamente. E um fim comum dos destinos os mais diversos, um oceano no qual vidas derivadas das camadas sociais as mais diversas flutuam juntas. [...] O que há de mais terrível na pobreza é o fato de que nela existem seres humanos cuja posição social é de pobres, e nada além de pobres. [...] uma classe cuja unidade se funda numa característica puramente passiva, a saber, pela maneira singular de a sociedade reagir e se conduzir em relação a ela (p.101).

Essa análise que ele faz da pobreza como “classe passiva" pode levar a considerá-la como uma "classe para o outro", ${ }^{16}$ constrangida a formar sua subjetividade a partir da objetivação que lhe é atribuída pelo "outro", na luta política. Esses indivíduos pobres são levados a se transformarem em "estrangeiros deles mesmos", afrontados por uma objetivação do "outro" que designa o que eles são, ou o que eles podem ser. Assim, a representação dominante está presente no âmbito do próprio discurso desses indivíduos considerados pobres pela coletividade. Mas a saída, apenas esboçada, encontra-se na condição de cidadania desses sujeitos.

A abordagem que ele faz da assistência aos pobres, em Les Pauvres, ultrapassa, portanto, a percepção das instituições da assistência como entidades exclusivamente objetivadas da ordem social - na forma de programas sociais -, impostas de fora aos indivíduos, mas implica uma experiência intersubjetiva do significado da dádiva (a caridade) e das funções do Estado em relação à pobreza e às instituições modernas. Nesse sentido, são, ao mesmo tempo, também coletivas, não se limitando às experiências restritas e individuais de quem dá para quem recebe, ou vice-versa.

Ele desenvolve essas observações num momento em que muitos sistemas de proteção contra riscos, em diversos países da Europa, foram implementados, tornando-se a assistência gradativamente uma política residual (Cf. Paugam;

${ }^{16}$ Fazendo aqui referência à distinção feita por Marx entre "classe em si" e "classe para si", Bourdieu analisa, no seu artigo "Une classe objet" (1977) a situação do campesinato que se impõe como um destino construído pelo outro. O campesinato, para ele, dentre todos os grupos dominados, é, sem dúvida, aquele que nunca construiu um contra-discurso capaz de se constituir em sujeito de sua verdade (p.4).
Shultheis, 1998, p.20). Segundo esses autores, com a legislação pioneira de Bismarck (1883-1889) na Alemanha, voltada para proteger os trabalhadores através de seguros sociais obrigatórios contra os riscos de acidentes de trabalho, doenças e a velhice, uma parte significativa das populações anteriormente assistidas foram transferidas para as categorias assumidas pelo seguro social. Entretanto, os assistidos representavam, ainda, um contingente importante daqueles excluídos do benefício do seguro, então restrito aos trabalhadores assalariados. Tratava-se, particularmente, de mulheres e crianças, mas também de famílias numerosas e monoparentais. As pessoas assistidas podiam pretender um direito formal ao auxílio, mas elas não dispunham de meios jurídicos de fazê-lo, enquanto os trabalhadores segurados tinham acesso jurídico gratuito. A estigmatização desses indivíduos se agravava, já que, na condição de assistidos, eles perdiam, à época, seus direitos civis, do voto, sendo relegados, assim, a cidadãos de segunda categoria (p.21).

Quando a pobreza é combatida e julgada intolerável pela coletividade no seu conjunto, seu estatuto social é desvalorizado e estigmatizante. Os pobres, por conseguinte, são mais ou menos levados a viver sua situação no isolamento. Eles buscam dissimular a inferioridade de seu estatuto no seu ambiente e mantêm relações distantes com os que estão próximos de sua condição. A humilhação os impede de desenvolver o sentimento de pertencimento a uma classe social (Paugam; Schulteis, 1998, p.18).

O fio da argumentação de Simmel é fundamental no estabelecimento das relações entre sociedade e política. Segundo Isaac Joseph (2003, p.325), Simmel considera que a política não é uma esfera à parte, mas, de alguma forma, uma categoria da experiência. Da mesma forma, a política não se reduz ao social, mas implica os termos do entendimento ou do não-entendimento dos participantes frente aos problemas. Assim, para Joseph, a questão da assistência, analisada por Simmel, exemplifica uma análise no campo político (como teleologia contratualista ou utilitarista). É que o "pobre", aquele indivíduo que se apresenta como excluído, pertence ao mais amplo dos círculos 
políticos, ou seja, à coletividade do Estado. ${ }^{17}$

Esse texto de Simmel levanta questões cruciais na discussão do desenho de sistemas de assistência contemporâneos: a questão da definição dos mínimos sociais; a diferenciação entre a obrigação da dádiva e da caridade em relação a agentes individuais privados e do Estado; o lugar da municipalidade na função das transferências sociais; as implicações metodológicas da análise do social, considerando variáveis políticas da cidadania e da cultura que estigmatizam o "lugar" desses sujeitos no corpo social, entre "úteis" e "inúteis”. No entanto, é preciso relativizar a perspectiva de passividade do "lugar" dos pobres nos textos de Simmel. A perspectiva de mudança na realidade social desses segmentos, por suas lutas e movimentos sociais, constitui expressão de uma cidadania conquistada e da superação de "lugares rígidos" no âmbito do corpo social. As lutas operárias gradativamente foram ampliando, para o conjunto da sociedade, direitos sociais, ainda que a centralidade desses direitos se ordenasse a partir da matriz corporativista da classe operária, na Alemanha e na França. No Brasil, a organização de muitos segmentos da cidadania em movimentos sociais, a exemplo da luta pela terra no Brasil, da luta por moradia, constituiu formas de superação desse lugar de "subalternidade" de muitos segmentos das classes populares em condição de pobreza, permitindo-lhes o acesso a várias políticas públicas e a direitos sociais.

Efetivamente, desde o século XVII, frente à emergência de uma massa de trabalhadores empobrecidos, a sociedade vem discutindo formas de assistência e reprodução social para as famílias trabalhadoras, até se chegar à proposição de uma medida científica de uma renda familiar para atender às necessidades básicas, como no estudo de Seebohm Rowntree: Poverty. A Study of Town Life [1901], da mesma época. Nesse sentido, as análises de Simmel, neste livro, contribuem para esclarecer alguns paradoxos entre a lógica daqueles que

${ }^{17}$ Num contexto de globalização, o maior dos campos políticos ultrapassaria a dimensão do Estado-nacional. concedem e o imperativo de um direito moral do pobre de receber, que acaba determinando uma obrigação da dádiva continuada, seja no plano público ou privado. Do mesmo modo, essa perspectiva de análise de Simmel pode auxiliar no entendimento das concepções liberais que limitam a ação pública da assistência social aos "mínimos" e aos mais pobres.

\section{SIMMEL E O PARADIGMA DA DÁDIVA: algu- mas considerações finais}

A obra de Georg Simmel alicerça uma concepção que vem sendo retomada na discussão contemporânea sobre programas de renda mínima cidadã, assentada num paradigma da dádiva. Simmel contrapõe-se ao entendimento restrito dos pobres como "inúteis no mundo", "população extranumerária”, “desqualificados” e "indesejáveis", situando-os em termos de direitos civis no contexto político republicano, com propostas atuais de direitos mínimos de cidadania. Nesse caso, a questão diz respeito à redistribuição.

A sua contribuição, portanto, pode subsidiar o debate atual sobre a natureza das proteções sociais. Além das questões relativas à abrangência de tais soluções, especialmente nas sociedades periféricas - em que a grandeza quantitativa do "excedente" da força de trabalho (o setor informal) torna ainda mais urgente e, ao mesmo tempo, mais complexa a ação do Estado -, essa colaboração recoloca, no centro do debate, as relações intrínsecas e contraditórias entre a proteção da cidadania e o universo do trabalho e dos trabalhadores.

Essas são questões abertas e polêmicas postas pelos encaminhamentos políticos contemporâneos. Chanial (2004), ao discutir propostas de renda mínima, identifica três paradigmas vigentes: $O$ paradigma do contrato, o paradigma do direito e o paradigma da dádiva. Segundo Chanial, o paradigma do contrato é defendido atualmente por Pierre Rosanvallon. Para esse autor, nenhuma renda pode estar desconectada de uma atividade de trabalho. O segundo refere-se a um paradigma do 
direito, defendido especialmente por J. M. Ferry (1995, 1996), que justifica essa renda integrando-a na construção dos direitos democráticos. O terceiro e último paradigma, o da dádiva, refuta o modelo do contrato e do direito, rearticulando, ao mesmo tempo, dádiva, incondicionalidade e cidadania (Caillé, 1987, 1992, 2000 apud Chanial, 2004).

Segundo Chanial, ${ }^{18}$ a perspectiva do contrato entende a renda incondicional como se fosse um direito sem contrapartida, um direito sem dever. A crítica é que sua implantação poderia criar um sistema de proteção social puramente indenizatório, na forma de um "Estado-Providência-passivo" (Rosanvallon, 1995, p.122-125). Na base da crítica do imaginário contratualista, está a idéia de equivalência, de que ninguém pode obter nada sem oferecer algo em troca e que a integração social pressupõe, portanto, a "utilidade social" ou o compromisso com a coletividade. Segundo essa perspectiva, a cidadania estaria ameaçada sempre que a reciprocidade de direitos e de deveres fosse quebrada, o que, para Rosanvallon, consiste na base de todo laço cívico. Mesmo se os direitos inerentes à cidadania pudessem justificar um direito à renda, um direito à vida, como analisa Simmel, esse direito não poderia estar separado de obrigações positivas. Todo direito à renda, para Rosanvallon (1995), supõe o direito ao trabalho, ou, utilizando os seus termos, supõe um dever de inserção ou de utilidade social. ${ }^{19}$

O paradigma da dádiva, para os autores do M.A.U.S.S. (Mouvement Anti-Utilitariste dans les Sciences Sociales, na França), ${ }^{20}$ rompe, de forma radical, com o imaginário contratualista (uma vez que, para esses autores, tem caráter econômico e utilitarista) e reafirma um duplo princípio da

${ }^{18}$ Sobre a teoria da dádiva, ver Caillé, 1998, 2002a; 2002b; Chanial, 1996, 2004; Laville; Caillé, 2001; Martins, 2002; Carvalho; Laville, 2004; Laville, 2004.

${ }^{19}$ Este registro da equivalência do contrato, segundo Chanial, é também o de Rawls. O imposto negativo, que complementa uma renda, supõe uma prestação de trabalho.

${ }^{20}$ No Brasil, o M. A. U. S. S. (Mouvement Anti-Utilitariste dans les Sciences Sociales) vem sendo divulgado pelo sociólogo Paulo Henrique Martins, professor Titular de Sociologia da UFPE, atual Vice-Presidente desse Movimento. Ver a respeito o site: www.jornaldomauss.org incondicionalidade: a incondicionalidade do valor das pessoas e aquela da própria cidadania democrática, como afirmou Simmel no seu livro Les pauvres [1907].

Para os adeptos do M.A.U.S.S, como Alain Caillé e Phillipe Chanial, a atribuição de uma renda desconectada da prestação de trabalho, hoje, consiste, primeiramente, em reconhecer igual dignidade a todos, independentemente de sua situação profissional, possibilitando a cada um escapar da miséria e dos estigmas identitários, como também da servidão e da humilhação próprias da assistência.

Para Chanial (2004), por exemplo, afirmar que o pacto democrático tem um valor intrínseco já significa sugerir que ele não seja cogitado sob a figura do contrato, e que a cidadania não seja encaminhada pelo cálculo dos direitos e das obrigações. Uma pessoa é legitima, porque, primeiramente, a fazemos cidadã. Em seguida é que podemos exigir dela qualquer civismo, e não o contrário. Nesse sentido, a cidadania distingue-se do registro do contrato, que obedece ao princípio inscrito na relação “é dando que se recebe". Ela não é paga. Ela deve ser incondicionalmente reconhecida, para que o indivíduo, autônomo, possa, de retorno, agir como cidadão. Tal é o sentido do desafio da renda incondicional da cidadania.

O esforço da busca de alternativas não é tarefa simples, por várias razões. Primeiramente, porque estamos falando de uma realidade submetida a mudanças radicais, na qual algumas dessas categorias ainda não foram suficientemente submetidas à crítica. E, por outro lado, porque, no campo dessas mudanças, patinamos sobre novos princípios e novas categorias de análise que, muitas vezes, aproximam tradições de pensamento opostas, como o liberalismo e o socialismo, como indica Lo Vuolo (2004) a respeito da renda mínima de cidadania. Essa zona cinzenta ${ }^{21}$ gera polissemia conceitual e pouca clareza quanto à direção da ação prática.

${ }^{21}$ Refiro-me ao caráter nebuloso e ainda pouco claro, porque subordinado a contextos conceituais e valorativos distintos. 
Como vimos, a contribuição do texto de Simmel, escrito no início do século XX, repercute sobre proposições analíticas, no presente, a respeito dos regimes de bem-estar e da idéia de criação de uma renda mínima de cidadania. Nesse sentido, algumas dimensões levantadas pelo autor podem auxiliar na avaliação crítica de proposições em curso, que expressem a necessidade de se ultrapassar uma abordagem puramente economicista, resgatando também dimensões políticas e culturais na compreensão dos processos de proteção e direitos sociais.

(Recebido para publicação em novembro de 2007) (Aceito em abril de 2008)

\section{REFERÊNCIAS}

BOURDIEU, Pierre. Une classe objet. Actes de la Recherche en Sciences Sociales, Paris, EHESS, n.17/18, p.2-5, nov., 1977

CAILLÉ, A. Nem holismo nem individualismo metodológico: Marcel Mauss e o paradigma da dádiva. Revista Brasileira de Ciências Sociais, São Paulo, ANPOCS, v.13, n.38, 1998.

. A antropologia do dom: o terceiro paradigma, Petrópolis, Vozes, 2002a;

. A dádiva e associação. In: MARTINS, P.H. (Org.) $A$ dádiva entre os modernos: discussão sobre os fundamentos e as regras do social. Petrópolis: Vozes; 2002b.

CARVALHO, G.; LAVILLE, I. L. Economia solidária: uma abordagem internacional. Porto Alegre: UFRGS, 2004.

CASTEL, R. Les métamorphoses de la question sociale. Une chronique du salariat. Paris: Fayard, 1995.

CHANIAL, P. Donner aux pauvres. Revue du M.A.U.S.S., Paris, n.7, 1996.

. Além do domínio do interesse? Dádiva, proteção social e renda da cidadania. Caderno CRH: revista do Centro de Recursos Humanos da UFBA, Salvador, v.17, n.40, p.17-32, jan./abr. 2004.

FERRY J.M. Revenu de citoyenneté, droit au travail, intégration sociale, Revue du M.A.U.S.S. Paris, La Découverte, n.7, 1996.

. L'allocation universelle. Paris: CERF, 1995.

JOSEPH, I. Le ressort politique de l'assistance, le moralisme et l'experience de l'induction morale. In: LES SDF (Sans Domicilie Fixe) Repésentations, trajectoires et politiques publiques. Paris: Ministère de l'Équipement, des Transports, du Logement, du Tourisme et de la Mer, 2003. p.321-345.

LAVILLE, J. L.; CAILLÉ, A. et al. Association, démocratie et société civile. Paris: La Découverte/ M.A.U.S.S./ CRIDA , 2001.

. Economia social y solidaria. Una visión europea. $\overline{\text { Buen }}$ os Aires: Altamira, 2004.
LO VUOLO, R. A modo de presentación: los conceitos del ingreso ciudadano. In: et al. Contra la exclusión. La propuesta del ingreso ciudadano. Buenos Aires: Miño y Dávila/CIEPP, 2004. p.17-51.

MARTINS, P.H. (Org.) A dádiva entre os modernos: discussão sobre os fundamentos e as regras do social, Petrópolis: Vozes, 2002.

MAUSS, Marcel. Essai sur le don. Forme et raison de l'échange dans les sociétés archaïques. Sociologie et Anthropologie. Paris: PUF, [1923-1924], p.145-171, 1991.

PAUGAM, S.; SHULTHEIS, F. Naissance d'une sociologie de la pauvrété. In: SIMMEL, G. Les pauvres. (Introdução). Paris: Presses Universitaires de France. Quadrige, 1998. p.1-34.

ROSANVALLON, P. La nouvelle question sociale. Répenser l'etat-providence. Paris: Ed. Seuil, 1995.

ROWNTREE, S. Poverty. A study of town life. Londres: Longmans, Green \&Co. [1901].

SIMMEL, G. Les pauvres. Paris: Presses Universitaires de France, [1907] 1998.

SUPLICY, E. M. Renda de cidadania: a saída é pela porta. 2.ed. rev. São Paulo: Cortez/Editora da Fundação Perseu Abramo, 2002

TOCQUEVILLE, A. de. Mémoire sur le paupérisme. Oeuvres complètes. Mélanges: 1958. tome XVI, p.117139.

VENDENBERGHE, F. As sociologias de Georg Simmel. Trad. Marcos Roberto Flamínio Peres. São Paulo: EDUSC/ Belém: EDUFPA, 2005. 
GEORG SIMMEL E A "SOCIOLOGIA DA POBREZA"

Anete B. L. Ivo

$\mathrm{O}$ artigo apresenta os principais aspectos tratados no livro Les Pauvres aspects treated in the book Les Pauvres [1907], de Georg Simmel, sobre os po- [1907], by Georg Simmel, on the poor bres e apobreza. O autor parte das rela- and poverty. The author starts from the ções intersubjetivas da obrigação $d a$ intersubjective relations of the obligation dádiva, no ato de dar/receber, avançan- of giving, in the action of giving/receiving, do em proposições teóricas mais am- advancing in ampler theoretical plas, como: as relações entre a ética, a propositions, such as: the relations moral e a sociedade; a articulação entre between ethics, morals and society; the o particular e o geral com base na posi- articulation between the particular and çẫo de dependência dos pobres frente à the general, based in the dependence coletividade; a passagem da noção abs- position of the poor regarding the trata da pobreza às formas regulatórias collectivity; the passage from the abstract da assistência e sua objetivação social notion of poverty to the regulatory na forma de instituições públicas e/ou forms of the assistance and its social privadas da assistência. Ao final o autor objectivation in the form of public and/ estabelece algumas conexões entre a or private institutions of assistance. At análise de Simmele per temporânea da teoria da dádiva em relação à proteção social, especialmente sobre a renda mínima de cidadania. Ao analisar a situação da pobreza, Simmel encaminha, no plano teórico e analítico, uma fecunda análise sobre a estruturação social.

Palavras-Chave: teoria social, Georg

Simmel, pobreza, teoria da dádiva, cida- Kurworbs: social theory, Georg Simme, dania. end the author establishes some de l'assistance. Pour finir, l'auteur établit

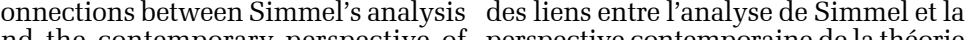
and the contemporary perspective of perspective contemporaine de la théorie theory of giving in relation to social des dons par rapport à la protection rotection, especially on the minimum sociale, tout spécialement en ce qui citizenship income. When analyzing concerne le revenu minimum de la the situation of poverty, Simmel directs, citoyenneté. En analysant la situation in the theoretical and analytical plan, a de la pauvreté, Simmel mène, autant fertile analysis about social structuring. sur le plan théorique que sur le plan

analytique, une analyse féconde de la KEYwORDS: social theory, Georg Simmel,
poverty, theory of the giving, citizenship.
Mots-clÉs: théorie sociale, Georg Simmel, pauvreté, théorie du don, citoyenneté. 